CCR1, BOB, Bonzo, CCR5 or CXCR4 (ref. 2) were infected with pseudotyped viruses (50 ng p24 per infection, $5 \times 10^{4}$ cells per well in 24 -well plates). 3T3.CD4 cells that stably express the different chemokine receptors ${ }^{2}$ were similarly infected. 3T3.CD4 cells expressing the new receptors were prepared by retroviral transduction with pMX.Bonzo and pMX.BOB. After 3 days, cells were resuspended in $120 \mu \mathrm{l}$ of luciferase lysis buffer (Promega). The luciferase activity in $20 \mu \mathrm{l}$ lysate was assayed in a Wallac Microbeta 1450 Counter using commercially available reagents (Promega).

Northern blots. Polyadenylated RNA was prepared from various human cell lines with the Micro-Fast Track kit (Invitrogen). Samples ( $5 \mu$ gNA) were electrophoresed through a $1 \%$ agarose-formaldehyde gel and transferred to a GeneScreen nitrocellulose membrane. Multiple-tissue northern blots I and II, purchased from Clontech, contain $\sim 2 \mu \mathrm{g}$ poly $(\mathrm{A})^{+}$RNA from each tissue. Integrity of blots was assayed by GAPDH probing. Full-length $\mathrm{CDNAs}$ of $\mathrm{BOB}$ and Bonzo were labelled with ${ }^{32} \mathrm{P}$ by using a Random Primed DNA-labelling kit (Boehringer-Mannheim) and used to probe northern blots.

Lymphocyte purification and RT-PCR. Monocytes were purified from buffy coats using a $46 \%$ Percoll gradient. To purify T- and B-cell subsets, PBMC were stained with phycoerythrin-conjugated anti-CD3 or anti-CD19 antibodies (Becton-Dickinson) and sorted using FACS (Coulter). Total RNA was isolated using RNAzol reagent (Cinna/Biotecx), treated with RNase-free DNase, and $0.5 \mu \mathrm{g}$ was taken for cDNA synthesis using Superscript II RNAse H reverse transcriptase and random hexamer primers (Gibco-BRL); one-twentieth of this reaction was used as a template for PCR amplification with Taq DNA polymerase. BOB primers used for RT-PCR: upstream (from ATG) 5' CATCTGCTCTTTGGTGATG; downstream ( $550 \mathrm{bp}$ from ATG), 5' GTATGGCTTATCATCAATCAGC, amplifies $\sim 600 \mathrm{bp}$ of transcript; Bonzo primers were: upstream (from $270 \mathrm{bp}$ downstream of ATG), 5' -CAGGCATCCATGAATGGGTGT, and downstream (from the stop codon), 5'-CAAGGCCTATAACTGGAACATGCTG, amplifies $\sim 750 \mathrm{bp}$ of transcript. The PCR reaction was run for 30 cycles at $94^{\circ} \mathrm{C}$ for $40 \mathrm{~s}, 58^{\circ} \mathrm{C}$ for $40 \mathrm{~s}$, and $72^{\circ} \mathrm{C}$ for $1 \mathrm{~min}$. To exclude contamination of genomic DNA, control cDNA reactions in which reverse transcriptase was omitted were prepared in parallel. These were uniformly negative.

Received 27 May; accepted 23 June 1997.

1. Feng, Y., Broder, C. C., Kennedy, P. E. \& Berger, E. A. HIV-1 entry cofactor: functional cDNA cloning of a seven-transmembrane, G protein-coupled receptor. Science 272, 872-877 (1996).

2. Deng, H. et al. Identification of a major co-receptor for primary isolates of HIV-1. Nature 381, 661666 (1996)

3. Alkhatib, G. et al. CC CKR5: a RANTES, MIP- $1 \alpha$, MIP- $1 \beta$ receptor as a fusion cofactor for macrophage-tropic HIV-1. Science 272, 1955-1958 (1996).

4. Dragic, T. et al. HIV-1 entry into $\mathrm{CD}^{+}$cells is mediated by the chemokine receptor CC-CKR-5. Nature 381, 667-673 (1996)

5. Doranz, B. J. et al. A dual-tropic primary HIV-1 isolate that uses fusin and the $\beta$-chemokine receptors CKR-5, CKR-3 and CKR-2b as fusion cofactors. Cell 85, 1149-1158 (1996).

6. Choe, H. et al. The beta-chemokine receptors CCR3 and CCR5 faciitate infection by primary HIV-1 isolates. Cell 85, 1135-1148 (1996).

7. Chen, Z., Zhou, P., Ho, D. D., Landau, N. R. \& Marx, P. A. Genetically divergent strains of simian immunodeficiency virus use CCR5 as a coreceptor for entry. J. Virol. 71, 2705-2715 (1997).

8. Marcon, L. et al. Utilization of C-C chemokine receptor 5 by the envelope glycoproteins of a pathogenic simian immunodeficiency virus, SIVmac239. J. Virol. 71, 2522-2527 (1997).

9. Edinger, A. L. et al. Differential utilization of CCR5 by macrophage and T cell tropic simian immunodeficiency virus strains. Proc. Natl Acad. Sci. USA 94, 4005-4010 (1997).

10. Hill, C. M. et al. Envelope glycoproteins from HIV-1, HIV-2, and SIV can use human CCR5 as a coreceptor for viral entry and make direct CD4-dependent interactions with this chemokine receptor. J. Virol. (in the press).

11. Marthas, M. L. et al. Rhesus macaques inoculated with molecularly cloned simian immunodeficiency virus. J. Med. Primatol. 18, 311-319 (1989).

12. Fukasawa, M. et al. Sequence of simian immunodeficiency virus from African green monkey, a new member of the HIV/SIV group. Nature 333, 457-461 (1988).

13. Clapham, P. R., Blanc, D. \& Weiss, R. A. Specific cell surface requirements for the infection of CD4 positive cells by human immunodeficiency virus types 1 and 2 and by simian immunodeficiency virus. Virology 181, 703-715 (1991).

14. Stefano, K. A. et al. Replication of a macrophage-tropic strain of human immunodeficiency virus type 1 (HIV-1) in a hybrid cell line, $\mathrm{CEM} \times 174$, suggests that cellular accessory molecules are required fo HIV-1 entry. J. Virol. 67, 6707-6715 (1993).

15. Heiber, M. et al. A novel human gene encoding a G-protein-coupled receptor (GPR15) is located on chromosome 3. Genomics 32, 462-465 (1996).

16. He, J. et al. CCR3 and CCR5 are co-receptors for HIV-1 infection of microglia. Nature 385, 645-649 (1997).

17. Fauci, A. S. Host factors and the pathogenesis of HIV-induced disease. Nature 384, 529-534 (1996). 18. Desrosiers, R. C. The simian immunodeficiency viruses. Annu. Rev. Immunol. 8, 557-578 (1990).

19. Kestler, H. et al. Induction of AIDS in rhesus monkeys by molecularly cloned simian immunodeficiency virus. Science 248, 1109-1112 (1990)

20. Theodorou, I., Meyer, L., Magierowska, M., Katlama, C. \& Rouzioux, C. HIV-1 infection in an individual homozygous for CCR5 delta 32. Seroco Study Group. Lancet 349, 1219-1220 (1997).

21. Biti, R. et al. HIV-1 infection in an individual homozygous for the CCR5 deletion allele. Nature Med. 3, 252-253 (1997)

22. O'Brien, T. R. et al. HIV-1 infection in a man homozygous for CCR5 delta 32. Lancet 349, 1219 (1997).
23. Kitamura, T. et al. Efficient screening of retroviral cDNA expression libraries. Proc. Natl Acad. Sci. USA 92, 9146-9150 (1995)

24. Landau, N. R., Page, K. A. \& Littman, D. R. Pseudotyping with human T-cell leukemia virus type I broadens the human immunodeficiency virus host range. J. Virol. 65, 162-169 (1991).

25. Westervelt, P., Gendelman, H. E. \& Ratner, L. Identification of a determinant within the human immunodeficiency virus 1 surface envelope glycoprotein critical for productive infection of primary monocytes. Proc. Natl Acad. Sci. USA 88, 3097-3101 (1991).

26. Hwang, S. S., Boyle, T. J., Lyerly, H. K. \& Cullen, B. R. Identification of envelope V3 loop as the major determinant of CD4 neutralization sensitivity of HIV-1. Science 257, 535-537 (1992).

27. Gao, F. et al. Molecular cloning and analysis of functional envelope genes from human immunodeficiency virus type 1 sequence subtypes A through G. (The WHO and NIAID Networks for HIV Isolation and Characterization.) J. Virol. 70, 1651-1657 (1996).

28. Barnett, S. W., Quiroga, M., Werner, A., Dina, D. \& Levy, J. A. Distinguishing features of an infectious molecular clone of the highly divergent and noncytopathic human immunodeficiency virus type 2 UC1 strain. J. Virol. 67, 1006-1014 (1993).

29. Kong, L. I. et al. West African HIV-2-related human retrovirus with attenuated cytopathicity. Science 240, 1525-1529 (1988).

30. Gao, F. et al. Human infection by genetically diverse SIVSM-related HIV-2 in west Africa. Nature 358, 495-499 (1992).

31. Liao, S. et al. J. Exp. Med. 185, 2015-2023 (1997).

Acknowledgements. We thank T. Kitamura for the pMX retroviral library; R. Sutton for construction of HIV-puro; C. Mackay for the monoclonal antibody against CCR5; P. Cresswell for 174 and CEM cell lines, B. Hahn for virus isolates; M. Emerman for pL-VSV-G; C. Weiss for HIV-2 Env vectors; G. Pare for technical assistance; W. Ellmeier for help with northern blots; and C. Davis, C. M. Hill and M. Vodicka for comments on the manuscript. This work was supported by grants from the $\mathrm{NIH}$ and by postdoctoral fellowships from the Aaron Diamond Foundation (H.-K.D.) and the Damon Runyon-Walter Winchell Foundation (V.N.K.). D.R.L. is an investigator of the Howard Hughes Medical Institute.

Correspondence and requests for materials should be addressed to D.R.L. (e-mail: littman@saturn.med. nyu.edu). Genbank sequence accession numbers are: human Bonzo, AF007545; BOB (African green monkey), AF007856; BOB (pigtailed macaque), AF007857; Bonzo (pigtailed macaque), AF007858; Bonzo (African green monkey), AF007859.

\section{X-linked IAP is a direct inhibitor of cell-death proteases}

\section{Quinn L. Deveraux*, Ryosuke Takahashi*, Guy S. Salvesen \& John C. Reed}

The Burnham Institute, Program on Apoptosis and Cell Death Research, 10901 North Torrey Pines Road, La Jolla, California 92037, USA

* These authors contributed equally to this work.

The inhibitor-of-apoptosis (IAP) family of genes has an evolutionarily conserved role in regulating programmed cell death in animals ranging from insects to humans ${ }^{1-6}$. Ectopic expression of human IAP proteins can suppress cell death induced by a variety of stimuli, but the mechanism of this inhibition was previously unknown. Here we show that human X-chromosome-linked IAP directly inhibits at least two members of the caspase family of celldeath proteases, caspase- 3 and caspase-7. As the caspases are highly conserved throughout the animal kingdom and are the principal effectors of apoptosis ${ }^{7}$, our findings suggest how IAPs might inhibit cell death, providing evidence for a mechanism of action for these mammalian cell-death suppressors.

For our initial investigation of human X-chromosome-linked IAP (XIAP; hILP; MIHA), we used recombinant XIAP protein and a cell-free system in which cytochrome $c$ was added to cytosolic extracts. When added to normal cytosol, cytochrome $c$ initiates an apoptotic programme which includes proteolytic processing and activation of certain caspases, and apoptotic-like destruction of exogenously added nuclei ${ }^{8}$. Release of cytochrome $c$ from mitochondria into the cytosol appears to be commonly associated with apoptosis $^{8,9}$.

Purified nuclei mostly remained intact in the cytosol from controls. In contrast, adding cytochrome $c$ caused apoptotic-like destruction of nearly all nuclei (Fig. 1A). Addition of cytochrome $c$ directly to nuclei without cytosol had no effect, demonstrating the requirement for cytosolic factors (results not shown $)^{8}$. Recombinant XIAP (rXIAP) added simultaneously with cytochrome $c$ severely inhibited nuclear destruction (Fig. 1A). An equivalent 
amount of added Bcl-2 protein had no protective effect.

In addition to nuclear destruction, XIAP also inhibited cytochrome- $c$-induced caspase activation. Two important proteolytic activities associated with caspases can be measured by assaying the cleavage of peptide substrates containing the sequences DEVD and YVAD: the former are recognized by most caspases and the latter by the ICE (caspase-1) subfamily (reviewed in ref. 10). Addition of cytochrome $c$ to extracts prepared from human 293 epithelial cells caused a rapid accumulation of DEVD-specific protease activity (Fig. 1B) but not of YVAD-specific cleavage (results not shown). The rXIAP protein markedly reduced cytochrome-cinduced generation of DEVD-cleaving activity in these extracts, whereas many control proteins had little or no effect even at $\geq 10$ fold molar excess over rXIAP (Fig. 1B). Results were similar when DEVD-specific hydrolysis was measured for cytosol from Jurkat Tcells, indicating that these findings are probably not unique to a single cell line (Fig. 1B). Furthermore, in cytosolic extracts prepared from 293T cells two days after transient transfection with either pcDNA3-XIAP or pcDNA3 control plasmid, cytochrome- $c$-induced activation of DEVD-cleaving proteases in vitro was reduced by $>$ $50 \%$ in the XIAP-overexpressing extracts compared to control extracts (not shown). Thus, both exogenously added rXIAP and endogenously produced XIAP inhibit cytochrome-c-induced caspase activation in vitro.

Addition of cytochrome $c$ to cytosolic extracts causes proteolytic processing of caspase-3 (CPP32; Yama; apopain) from its $\sim 32 \mathrm{~K}$ zymogen precursor into active large and small subunits ${ }^{8}$ - a result we confirmed by immunoblotting using a rabbit antiserum specific for the zymogen and large subunit of this protease (Fig. 1C). In contrast, addition of rXIAP protein markedly inhibited cytochrome-c-induced cleavage of the caspase- 3 zymogen (Fig. 1C). Equivalent concentrations of several control proteins (glutathione-Stransferase (GST), GST-Bcl-2, GST-Bax, GST-CD40) had no effect on caspase-3 processing (result not shown).

As an alternative way to induce apoptotis in these extracts, we added recombinant, active caspase-8 (FLICE; Mach; Mch5), a protease that associates with Fas and TNF-R1 receptor complexes and functions as an upstream initiator of proteolytic cascades that lead to caspase- 3 activation and apoptosis ${ }^{11-14}$. Caspase- 8 stimulated cleavage of caspase-3, yielding large-subunit bands characteristic of protease activation (Fig. 1C). In the presence of XIAP, caspase- 8 induced a partially processed form of caspase- 3 , presumably by cleavage between the large and small subunits without the subsequent removal of the $\mathrm{N}$-terminal peptide 'prodomain ${ }^{15}$. XIAP thus did not prevent the initial cleavage of caspase- 3 induced (perhaps directly) by caspase- 8 , but did inhibit the subsequent processing to the mature large subunit. XIAP also inhibited caspase8 -induced destruction of nuclei and the accumulation of DEVDspecific protease in extracts (not shown), indicating that it interferes with a protease(s) downstream of caspase- 8 .

As XIAP prevents the completion of caspase- 3 processing in extracts treated with caspase-8, XIAP might directly inhibit this protease, given that removal of the $\mathrm{N}$-terminal prodomain of caspase-3 occurs by autocatalysis ${ }^{15,16}$. We therefore tested the effect of rXIAP on the activity of several purified and active recombinant caspases in vitro. Purified GST-XIAP inhibited $>95 \%$ of DEVDpeptide cleavage by caspase- 3 and by the closely related caspase- 7 (LAP3/Mch3) when added at a $\sim 10$-fold molar excess, but did not affect substrate cleavage by caspases $8,6(\mathrm{Mch} 2)$ or 1 , even at 50 -fold molar excess (Fig. 2a). Even a 2-fold molar excess of XIAP was sufficient to inhibit $>70 \%$ of caspase- 3 and $\sim 100 \%$ of caspase- 7 activity when assayed at high enzyme concentrations $(0.5-0.7 \mu \mathrm{M})$ and with XIAP added before $100 \mu \mathrm{M}$ DEVD-pNA substrate. A GSTfusion protein containing only the three BIR (baculovirus IAP repeat) domains of XIAP (residues 1-336) also potently inhibited caspase- 3 and caspase-7 in vitro, whereas a GST fusion containing the RING domain (residues 337-497), as well as several control
A

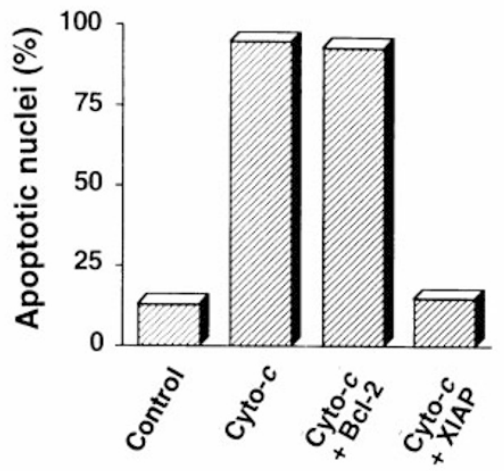

B

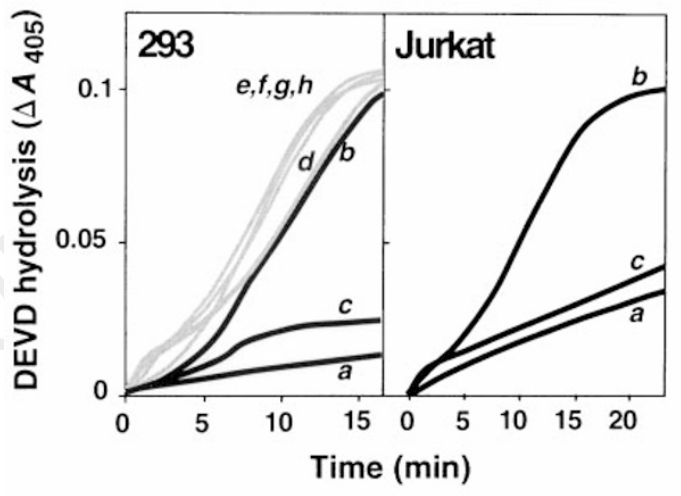

C

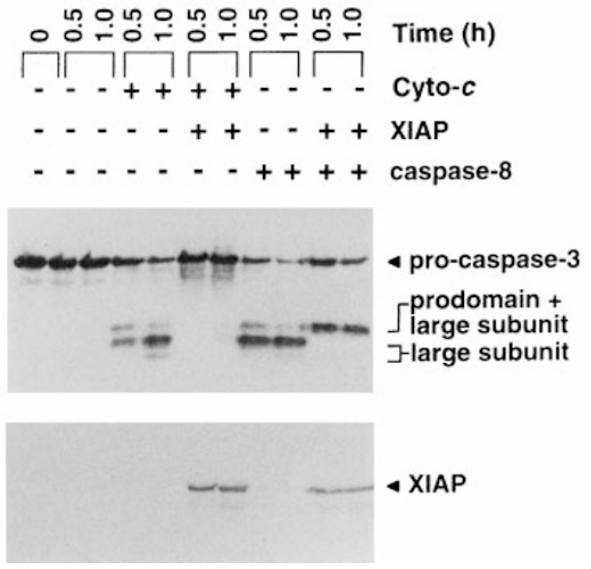

Figure 1 XIAP inhibits cytochrome-c-induced processing of caspase-3 and destruction of nuclei in cytosolic extracts. A, Isolated nuclei were added to cytosolic extracts, followed by $10 \mu \mathrm{M}$ cytochrome $c$ and $1 \mathrm{mM}$ dATP, with or without GST-XIAP $(0.4 \mu \mathrm{M})$ or GST-Bcl-2 $(0.4 \mu \mathrm{M})$, and the percentage of nuclei with apoptotic features was determined (data representative of 2 of 2 experiments). B, Cytosolic extracts from 293 or Jurkat cells were used as a control (a) or were treated with $1 \mu \mathrm{M}$ cytochrome $c$ and $1 \mathrm{mM}$ dATP alone (b), or with $\sim 0.2 \mu \mathrm{M}$ GST-XIAP (c). Controls (grey lines) consisted of addition of $\sim 10 \times$ more $(\sim 2 \mu \mathrm{M})$ control GST-fusion proteins, including GST-Bcl-2 (d), GST-Bax (e), GST-NM23 (f) and GST-CD40 cytosolic domain $(\mathbf{g})$, or addition of $5 \mu \mathrm{M} \mathrm{His}{ }_{6}$-S5a protein (h). DEVD-pNA hydrolysis was then measured at various times (data representative of several experiments performed with independent GST-XIAP preparations). C, Immunoblot analysis for caspase-3 was performed using cytosolic extracts ( $50 \mu \mathrm{g}$ per lane) before or at 0.5 and $1.0 \mathrm{~h}$ after adding either cytochrome $c$ and dATP or active caspase-8 proteases $(\sim 1 \mu \mathrm{g})$, with (+) or without (-) $\sim 0.2 \mu \mathrm{M}$ GST-XIAP (30- $\mu$ l reaction volumes). The positions are noted for the pro-enzyme, partially processed caspase-3 (large subunit + prodomain) and the large subunit forms of fully processed caspase-3. The blot was also probed with anti-XIAP antiserum (lower panel). 
GST-fusion proteins, had no significant effect (not shown). The inhibition of caspase- 3 and caspase-7 by XIAP was concentrationdependent (Fig. 2b,c). Based upon progress curve analysis, XIAP demonstrated tight, reversible binding to caspase- 3 and caspase-7 with inhibition constants of $\sim 0.7$ and $\sim 0.2 \mathrm{nM}$, respectively. These values compare favourably with viral inhibitors of caspases (cowpox CrmA: $0.01-0.95 \mathrm{nM}$; baculovirus p35: $1.0 \mathrm{nM}$ for their target (aspases) $)^{17,18}$.

Besides inhibiting the proteolytic activity of caspase- 3 and caspase-7, XIAP also bound directly to these proteases in vitro. For example, mixing purified GST-XIAP protein or GST-CD40 (negative control) immobilized on glutathione-Sepharose with purified recombinant caspases revealed specific binding of XIAP to caspase- 3 and caspase- 7 but not to caspases 1,6 or 8 (Fig. 2 d, and data not shown). Specific binding to caspase- 3 and caspase-7 was also observed when in vitro translated ${ }^{35} \mathrm{~S}$-labelled Myc-tagged XIAP was tested for binding to $\mathrm{His}_{6}$-tagged active proteases immobilized on Ni resin (not shown). XIAP, however, did not bind efficiently to the unprocessed pro-enzymes, based on similar experiments in which immobilized GST-XIAP was assayed for binding to unprocessed caspase- 3 and caspase- 7 in cytosolic extracts (Fig. 2e,f). In contrast, after treatment of the same extracts with cytochrome $c$, processed caspase- 3 and caspase- 7 then bound to immobilized GST-XIAP but not GST-CD40. The partially processed caspase-3 seen in extracts treated with the combination of caspase- 8 and rXIAP (Fig. 1C) also bound efficiently to immobilized GST-XIAP (not shown), consistent with the idea that cleavage between the large and small subunit but not removal of the prodomain is required for protease activation. Taken together, these data indicate that XIAP directly binds active caspase- 3 and caspase-7, but not the inactive zymogens.

To determine whether XIAP can inhibit processing and activation of caspases in intact cells, we did transient transfection experiments in human 293T cells using overexpression of Bax protein as a a

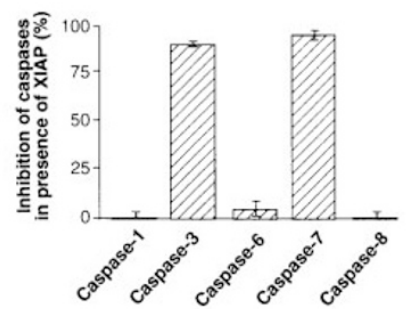

d
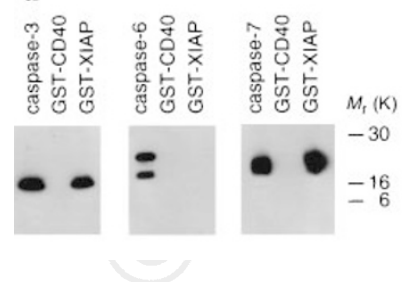

b

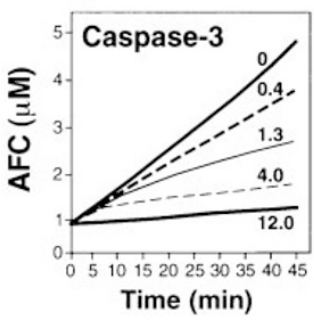

pro- $\rightarrow$
caspase-3
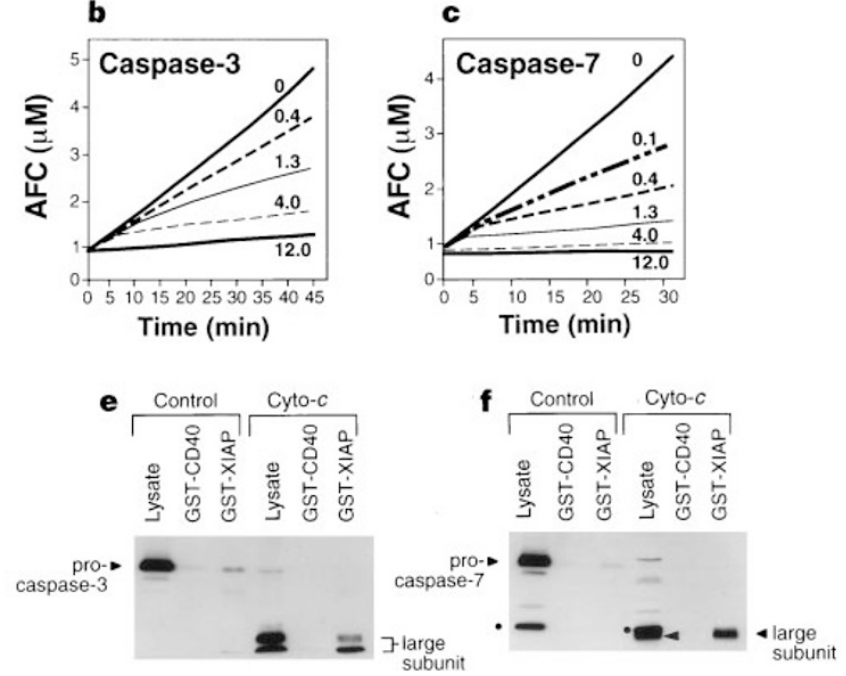

Figure 2 XIAP directly binds and inhibits caspase-3 and caspase-7. a, Purified recombinant caspases $1,3,6,7$ and $8(1-10 \mathrm{nM})$ were incubated with or without up to a 50-fold molar excess of XIAP (10-50 nM range). Data are expressed as per cent inhibition, based on the average ratio of velocities $\left(V_{\mathrm{i}} / V_{0}\right)$ of three independent experiments (mean \pm s.e.) performed in the presence $\left(V_{i}\right)$ or absence $\left(V_{0}\right)$ of GSTXIAP. b, c, Representative progress curves are shown for caspase-3 $(0.05 \mathrm{nM})$ and caspase-7 (0.1 nM), respectively, in which XIAP was added at various concentrations (nM) simultaneously with substrate (100 $\mu$ M DEVD-AFC). d, GST-XIAP or
GST-CD40 on glutathione-Sepharose were tested for binding to active recombinant proteases by immunoblotting. As a control, purified proteases $(0.1 \mu \mathrm{g})$ were run directly in the gel. e, f, GST-XIAP or GST-CD40 fusion proteins immobilized on glutathione-Sepharose were assayed by immunoblotting for binding to caspase-3 (e) or caspase-7 (f) in untreated ('control') 293 cytosolic extracts or after activation with cytochrome c. As a control, lysates $(50 \mu \mathrm{g})$ were run directly in gels. A nonspecific band detected by the caspase-7 antiserum in cell lysates is indicated by a dot to distinguish it from the processed $\sim 20 \mathrm{~K}$ large subunit.

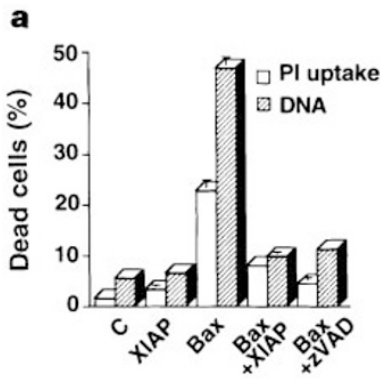

c

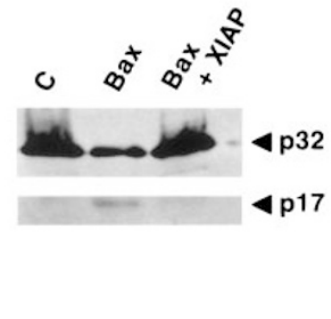

Figure 3 XIAP inhibits Bax-induced caspase-3 processing and cell death in 293T cells. a, The percentage of dead (uptake of propidium iodide) and apoptotic *hypodiploid DNA content) cells (mean \pm s.e. for 3 determinations) was determined 1 day after transfection of 293T cells with pcDNA3 ('C'), pcDNA3-Bax, pcDNA3-Myc-XIAP, or pcDNA3-Bax and pcDNA3-Myc-XIAP. ZVAD-fmk (50 $\mu \mathrm{M})$
(Bachem) was added immediately after Bax-transfection. Extracts were prepared from transfected cells for either $\mathbf{b}$, protease assay (DEVD-AFC cleavage activity; expressed as relative fluorescence units, RFU), or c, immunoblot analysis of caspase-3 processing. Different exposure was used for $32 \mathrm{~K}$ pro- and $17 \mathrm{~K}$ processed caspase-3. 
stimulus for inducing apoptosis and caspase-3 activation. Previously Bax had been shown to induce mitochondrial permeability transition (predicted to cause the release of cytochrome $c$ ) and processing of caspases 3, 6 and 7 (ref. 19). Transfection of a Baxencoding plasmid into $293 \mathrm{~T}$ cells caused an approximately 8-10fold increase in cell death (as measured by trypan-blue or propidium iodide uptake) about an 8-10-fold increase in apoptosis (as measured by DNA fragmentation) compared to control transfected cells (Fig. 3a). In contrast, when Bax- and XIAP-encoding plasmids were co-transfected, Bax-mediated cell death and apoptosis were inhibited $(P<0.01 ; t$-test $)$. Immunoblotting confirmed that the Myc-tagged XIAP protein was expressed in the expected transfected cells and verified that XIAP did not inhibit production of Bax protein (not shown), implying that XIAP blocks an event downstream of Bax. A Myc-tagged version of XIAP containing only the BIR domains was as effective as the fulllength protein at suppressing Bax-induced apoptosis, whereas the RING domain of XIAP was inactive (the percentages of apoptotic cells, based on hypodiploid DNA content, were $11 \pm 1 \%$ (neo control), $53 \pm 2 \%$ (Bax), $15 \pm 0.5 \%$ (Bax + XIAP), $18 \pm 1 \%$ $(\mathrm{Bax}+\mathrm{BIRs}), 47 \pm 1 \%(\mathrm{Bax}+\mathrm{RING}))$. The caspase-inhibiting peptide zVAD-fmk also inhibited Bax-induced apoptosis in 293T cells, consistent with a role for caspases in Bax-triggered cell death in these cells.

Extracts prepared from Bax-transfected 293T cells also contained much more caspase activity and processed caspase- 3 than did control transfected cells. In contrast, analysis of extracts from cells co-transfected with Bax and XIAP revealed that XIAP markedly inhibited Bax-induced generation of caspase activity (Fig. 3b) and caspase-3 processing (Fig. 3c). This suppression of caspase-3 processing in cells (Fig. 3c) and cytosolic extracts in vitro (Fig. 1c) implies that XIAP either blocks the activity of caspases upstream of caspase-3 or that it prevents caspase-3-mediated processing of procaspase-3.

We have described, to our knowledge for the first time, a mechanism of action for an IAP-family protein: namely, inhibition of active cell-death proteases. Although viral proteins such as CrmA and p35 bind to and inhibit caspases, XIAP is the first cellular protein identified with these characteristics. The extensive homology shared by IAP-family proteins across evolution (particularly in the BIR domains) suggests that other members of this family of apoptosis-suppressing proteins also inhibit specific caspases. Although apoptosis seems uniformly to require the participation of caspases ${ }^{20}$, the particular caspases necessary vary according to cell-type and the stimulus triggering cell death ${ }^{21,22}$. Therefore, the ability of each IAP family member to inhibit apoptosis may also vary, depending on the cell and the stimulus involved. XIAP, for instance, may be an effective inhibitor only of apoptotic stimuli that depend on caspase-3 and/or caspase-7. Further experiments will determine in which cell-types and under which apoptosis-stimulating conditions XIAP effectively prevents apoptosis.

\section{Methods}

Expression and purification of proteins. A XIAP-encoding cDNA was obtained by RT-PCR using a first-strand cDNA derived from Jurkat cells as the template and specific primers based upon Genbank accession number U32974 (forward primer, 5'-GGGAATTCATGACTTTTAACAGTTTTGAAGGAT-3'; reverse primer, $5^{\prime}$-CTCTCGAGCATGCCTACTATAGAGTTAGA-3'). The PCR product was digested with EcoRI and XhoI, followed by ligation into pcDNA3 (Invitrogen) containing an N-terminal Myc tag and into pGEX4T-1 (Pharmacia). Plasmid pGEX4T-1-XIAP was then introduced into an E. coli strain BL21(DE3) harbouring the plasmid pT-Trx ${ }^{23}$. The GST-XIAP fusion protein was prepared from the soluble fraction upon induction with $0.2 \mathrm{mM}$ IPTG at $30^{\circ} \mathrm{C}$ for $3 \mathrm{~h}$, affinity-purified using glutathione-Sepharose, and then dialysed against PBS.

Full-length cDNAs encoding caspases 3,6 and 7, and a cDNA encoding the catalytic subunits of caspase- 8 (Ser $216 \rightarrow$ C terminus) were subcloned into
pET vectors (Novagen), expressed in E. coli strain BL21(DE3)pLysS as His $_{6}$ tagged proteins, and purified as described ${ }^{14,16,17}$. The preparation of recombinant control proteins, GST-Bcl-2, GST-Bax, GST-CD40 cytosolic domain and $\mathrm{His}_{6}$-S5a proteasome subunit, has been described ${ }^{24-26}$.

Enzyme assays. Caspase activity was assayed by release of 7-amino-4trifluoromethyl-coumarin (AFC) or $p$-nitroanilide (pNA) from YVAD- or DEVD-containing synthetic peptides using continuous-reading instruments as described ${ }^{17}$. Inhibition rates and equilibria were determined by progress curves in which DEVD-AFC hydrolysis was measured using $\sim 0.1 \mathrm{nM}$ caspases and a range of concentrations of $\operatorname{rXIAP}(0.1-12 \mu \mathrm{M}) . K_{\mathrm{i}}$ was calculated without any assumption of the inhibitory mechanism, and therefore without adjustment for the $0.1 \mathrm{mM}$ DEVD-AFC substrate concentration ${ }^{17}$. The specific activities of the enzymes $\left(k_{\mathrm{cat}} / K_{\mathrm{m}}\right)$ were estimated using Ac-YVAD-AFC for caspase-1 and Ac-DEVD-AFC for all others, and ranged from $1.3 \times$ $10^{4} \mathrm{M}^{-1} \mathrm{~s}^{-1}$ for caspase-8 to $1.3 \times 10^{6} \mathrm{M}^{-1} \mathrm{~s}^{-1}$ for caspase-3 (Q. Zhou and G.S.S., manuscript in preparation).

Preparation and induction of the cell-free apoptotic system. Cell extracts were prepared as described $^{8}$, but with several modifications, using 293 embryonic kidney or Jurkat T cells. Cells were washed with ice-cold buffer A (20 mM HEPES (pH 7.5), $10 \mathrm{mM} \mathrm{KCl,} 1.5 \mathrm{mM} \mathrm{MgCl}_{2}, 1 \mathrm{mM}$ EDTA, $1 \mathrm{mM}$ DTT and $0.1 \mathrm{mM}$ PMSF) and suspended in one volume of buffer A. Cells were incubated on ice for $20 \mathrm{~min}$ and then disrupted either by passage through a 26gauge needle 15 times (293 cells) or Dounce-homogenized 15 times in $2 \mathrm{ml}$ buffer using a B-type pestle (Jurkat T-cells). Cell extracts (10-15 mg total protein per $\mathrm{ml}$ ) were clarified by centrifugation at $16,000 \mathrm{~g}$ for $30 \mathrm{~min}$ and the $\mathrm{NaCl}$ concentration increased by $50 \mathrm{mM}$. For initiating caspase activation, $1 \mu \mathrm{M}$ horse heart cytochrome $c$ (Sigma) and $1 \mathrm{mM}$ dATP were added. Nuclei were prepared from HeLa cells ${ }^{15}$ and stained with $0.1 \mu \mathrm{g} \mu \mathrm{l}^{-1}$ of acridine orange or ethidium bromide.

Immunoblot analysis. Immunoblotting for caspases was done as described, using $750 \mathrm{mM}$ Tris/12\% polyacrylamide gels, after normalizing cell lysates for protein content ${ }^{27,28}$. Antiserum specific for XIAP was prepared in rabbits using a synthetic peptide $\mathrm{NH}_{2}$-CDAVSSDRNFPNSTNLPRNPS-amide (amino acids 241-261) conjugated to maleimide-activated keyhole limpet haemocyanin and ovalbumin carrier proteins (Pierce).

Protein-binding assays. GST-XIAP $(\sim 3 \mu \mathrm{g})$ or GST-CD40 $(\sim 6 \mu \mathrm{g})$ immobilized on glutathione-Sepharose $(5 \mu \mathrm{l})$ was added to $50-\mu \mathrm{l}$ cytosolic extracts (preincubated with or without $1 \mu \mathrm{M}$ cytochrome $c$ and $1 \mathrm{mM} \mathrm{dATP}$ for $60 \mathrm{~min}$ at $\left.30^{\circ} \mathrm{C}\right)$ or to purified caspases $(0.5 \mu \mathrm{g}$ caspase 3,6 or 7$)$ in $100 \mu \mathrm{l}$ caspase assay buffer ${ }^{16}$ with $0.1 \%(\mathrm{w} / \mathrm{v})$ BSA. After incubation at $4{ }^{\circ} \mathrm{C}$ for $60 \mathrm{~min}$, beads were removed by centrifugation and washed twice with 100 volumes of $50 \mathrm{mM}$ Tris, $\mathrm{pH}$ 7.5, $150 \mathrm{mM} \mathrm{KCl}, 2 \mathrm{mM}$ DTT, 0.025\% Triton-X100 before SDS-PAGE and immunoblot assay.

Transfection of cultured cells. Subconfluent $293 \mathrm{~T}$ cells were transfected in 6$\mathrm{cm}$ dishes using the calcium phosphate method with $1 \mu \mathrm{g}$ pcDNA3-humanBax and either $9 \mu \mathrm{g}$ control plasmid pcDNA3 or pcDNA3-Myc-XIAP. Transfection efficiency was $80-90 \%$ (based on X-gal staining following cotransfection of pCMV- $\beta \mathrm{Gal})$. After culturing for $24 \mathrm{~h}$, both the floating and attached cells were collected and the percentage of dead cells was determined by either trypan-blue or propidium iodide (PI) dye exclusion. Apoptotic cells containing subdiploid DNA were quantified by FACS analysis of PI-stained, ethanol-fixed cells. The remaining cell pellets were lysed in $10 \mathrm{mM}$ HEPES, pH 7.5, 142 mM KCl, 1 mM EGTA, 1 mM DTT, 0.2\% NP-40, 0.1 mM PMSF and used for either immunoblot analysis or protease assay.

Received 21 February; accepted 12 May 1996.

1. Clem, R. J. \& Miller, L. K. Control of programmed cell death by the baculovirus genes p35 and iap. Mol. Cell. Biol. 14, 5212-5222 (1994).

Roy, N. et al. The gene for neuronal apoptosis inhibitory protein is partially deleted in individuals with spinal muscular atrophy. Cell 80, 167-178 (1995).

3. Rothe, M., Pan, M.-G., Henzel, W. J., Ayres, T. M. \& Goeddel, D. V. The TNFR2-TRAF signaling complex contains two novel proteins related to baculoviral inhibitor of apoptosis proteins. Cell 83, 1243-1252 (1995).

4. Duckett, C. S. et al. A conserved family of cellular genes related to the baculovirus iap gene and encoding apoptosis inhibitors. EMBO J. 15, 2685-2694 (1996).

5. Uren, A. G., Pakusch, M., Hawkins, C. J., Puls, K. L. \& Vaux, D. L. Cloning and expression of apoptosis inhibitory protein homologs that function to inhibit apoptosis and/or bind tumor necrosis factor receptor-associated factors. Proc. Natl Acad. Sci. USA 93, 4974-4978 (1996).

6. Hay, B. A., Wassarman, D. A. \& Rubin, G. M. Drosophila homologs of baculovirus inhibitor of apoptosis proteins function to block cell death. Cell 83, 1253-1262 (1995).

7. Alnemri, E. S. et al. Human ICE/CED-3 protease nomenclature. Cell 87, 171 (1996).

8. Liu, X., Kim, C. N., Yang, J., Jemmerson, R. \& Wang, X. Induction of apoptotic program in cell-free 
extracts: requirement for dATP and cytochrome c. Cell 86, 147-157 (1996).

Kluck, R. M., Bossy-Wetzel, E., Green, D. R. \& Newmeyer, D. D. The release of cytochrome $c$ from mitochondria: a primary site for Bcl-2 regulation of apoptosis. Science 275, 1132-1136 (1997).

10. Martin, S. J. \& Green, D. R. Protease activation during apopotosis: death by a thousand cuts? Cell $\mathbf{8 2}$, 349-352 (1995)

11. Muzio, M. et al. Flice, a novel FADD-homologous ICE/CED-3-like protease, is recruited to the CD95 (Fas/APO-1) death-inducing signaling complex. Cell 85, 817-827 (1996).

12. Boldin, M. P., Goncharov, T. M., Goltsev, Y. V. \& Wallach, D. Involvement of MACH, a novel MORT1/ FADD-interacting protease, in Fas/APO-1 and TNF receptor-induced cell death. Cell 85, 803-815 (1996).

13. Srinivasula, S., Ahmad, M., Fernandes-Alnemri, T., Litwack, G. \& Alnemri, E. S. Molecular ordering o the fas-apoptotic pathway: The fas/APO-1 protease Mch5 is a CrmA-inhibitable protease that activates multiple Ced-3/ICE-like cysteine proteases. Proc. Natl Acad. Sci. USA 93, 14486-1449 (1996).

14. Muzio, M., Salvesen, G. S. \& Dixit, V. M. FLICE induced apoptosis in a cell-free system. J. Biol. Chem 272, 2952-2956 (1997)

15. Martin, S. J. et al. Cell-free reconstitution of Fas-, UV radiation- and ceramide-induced apoptosis. EMBO J. 14, 5191-5200 (1995).

16. Quan, L. T. et al. Proteolytic activation of the cell death protease Yama/CPP32 by granzyme B. Proc Natl Acad. Sci. USA 93, 1972-1976 (1996).

17. Zhou, Q. et al. Target protease specificity of the viral serpin CrmA: analysis of five caspases. J. Biol. Chem. 272, 7797-7800 (1997).

18. Bertin, J. et al. Apoptotic suppression by baculovirus p35 involves cleavage by and inhibition of virus-induced CED-3/ICE-like protease. J. Virol. 70, 6251-6259 (1996).

19. Xiang, J., Chao, D. T. \& Korsmeyer, S. J. BAX-induced cell death may not require interleukin $1 \beta$ converting enzyme-like proteases. Proc. Natl Acad. Sci. USA 93, 14559-14563 (1996).

20. Weil, M. et al. Constitutive expression of the machinery for programmed cell death. J. Cell Biol. 133 1053-1059 (1996)

21. Kuida, K. et al. Altered cytokine export and apoptosis in mice deficient in interleukin-1 $\beta$ converting enzyme. Science 267, 2000-2003 (1995).

22. Kuida, K. et al. Decreased apoptosis in the brain and premature lethality in CPP32-deficient mice Nature 384, 368-372 (1996)

23. Yamakawa, T. et al. Increase of solubility of foreign proteins in Escherichia coli by coproduction of the bacterial thioredoxin. J. Biol. Chem. 270, 25328-25331 (1995).

24. Hanada, M., Aimé-Sempé, C., Sato, T. \& Reed, J. C. Structure-function analysis of Bcl-2 protein: identification of conserved domains important for homodimerization with Bcl-2 and heterodimerization with Bax. J. Biol. Chem. 270, 11962-11968 (1995).

25. Sato, T., Irie, S. \& Reed, J. C. A novel member of the TRAF family of putative signal transducing proteins binds to the cytosolic domain of CD40. FEBS Lett. 358, 113-118 (1995).

26. Deveraux, Q., van Nocker, S., Mahaffey, D., Vierstra, R. \& Rechsteiner, M. Inhibition of ubiquitinmediated proteolysis by the Arabidopsis 26 S protease subunit S5a. J. Biol. Chem. 270, 29660-29663 (1995).

27. Krajewski, S. et al. Immunolocalization of the ICE/Ced-3-family protease, CPP32 (caspase-3), in nonHodgkin's lymphomas (NHLs), chronic lymphocytic leukemias (CLL), and reactive lymph nodes. Blood (in the press).

28. Orth, K., O’Rourke, K., Salvesen, G. S. \& Dixit, V. M. Molecular ordering of apoptotic mammalian CED-3/ICE-like proteases. J. Biol. Chem. 271, 20977-20980 (1996).

Acknowledgements. We thank A. Price and Q. Zhou for technical assistance, N. Roy, M. Ellerby, and L. Ellerby for discussion, N. Thornberry for ICE and V. Dixit for some protease-encoding cDNAs and antibodies.

Correspondence and requests for materials should be addressed to J.C.R. (e-mail: jreed@licrf.edu)

\section{Drosophila Mad binds to DNA} and directly mediates activation of vestigial by Decapentaplegic

\section{Jaeseob Kim*, Kirby Johnson $\dagger$, Hui Ju Chen $\ddagger$, Sean Carroll ${ }^{*} \uparrow$ \& Allen Laughon $\dagger$}

${ }^{*}$ Howard Hughes Medical Institute and Laboratory of Molecular Biology, University of Wisconsin, 1525 Linden Drive, Madison, Wisconsin 53706, USA $\dagger$ Departments of Genetics and Medical Genetics, 445 Henry Mall, University of Wisconsin-Madison, Madison, Wisconsin 53706, USA $\$$ Department of Oncology, McArdle Laboratory, University of Wisconsin-Madison, Madison, Wisconsin 53706, USA

The TGF- $\beta$ (transforming growth factor- $\beta$ )-related signalling proteins, including Decapentaplegic (Dpp) in Drosophila and bone morphogenic proteins and activin in vertebrates, affect the growth and patterning of a great variety of structures. However, the mechanisms by which these ligands regulate gene expression are not understood. Activation of complexes of type I with type II receptors results in the phosphorylation and nuclear localization of members of the SMAD protein family ${ }^{1-9}$, which are thought to act as co-activators of transcription, perhaps in conjunction with sequence-specific cofactors ${ }^{10}$. Here we show that the aminoterminal domain of the Drosophila Mothers against dpp protein (Mad), a mediator of Dpp signalling ${ }^{11-14}$, possesses a sequencespecific DNA-binding activity that becomes apparent when carboxy-terminal residues are removed. Mad binds to and is required for the activation of an enhancer within the vestigial wingpatterning gene in cells across the entire developing wing blade. Mad also binds to Dpp-response elements in other genes. These results suggest that Dpp signalling regulates gene expression by activating Mad binding to target gene enhancers.

In the Drosophila wing imaginal disc, the anteroposterior and dorsoventral compartment boundaries are important signalling sources, and inputs from both axes are required for appendage formation ${ }^{15}$. Growth and patterning along the anteroposterior axis depends upon the sequential organizing activities of the Engrailed (En), Hedgehog (Hh) and Decapentaplegic (Dpp) proteins ${ }^{16-19}$. Dpp acts as a morphogen from its source to organize wing growth and anteroposterior patterning and to activate gene expression over a long range $\mathrm{e}^{19-24}$. The spalt $(\mathrm{sal})^{25}$ and optomotor-blind $(\mathrm{omb})^{26}$ genes are expressed in nested patterns centred on and extending up to 20 cell-diameters away from the stripe of Dpp expression $^{22,23}$ (Fig. 1a). The vestigial ( $v g$ ) gene is even more broadly expressed and is required in all cells of the developing wing (Fig. 1a). Activation of $v g$ is regulated by signals from both axes through separate cis-regulatory elements that control complementary patterns of gene expression ${ }^{24}$. The 'boundary' enhancer is activated along the dorsoventral boundary through components of the Notch pathway, whereas the 'quadrant' enhancer is activated in the remainder of the developing wing blade (Fig. 1e) by Dpp as well as a signal from the dorsoventral boundary ${ }^{24}$.

Because Mad is an intracellular signal transducer downstream of Dpp receptors ${ }^{1,13,14}$, we examined the requirement of Mad activity for $\mathrm{Vg}$ expression in the wing imaginal disc in mitotic clones with reduced Mad function. Homozygous clones for the strong $\mathrm{Mad}^{1.2}$ allele in developing wing-blade cells had significantly reduced levels of $\mathrm{Vg}$ expression and showed a growth disadvantage in comparison with surrounding heterozygous or wild-type cells (twin spot) (Fig. $1 \mathrm{~b}-\mathrm{d}$, arrows). In contrast, $\mathrm{Mad}^{1.2}$ clones along the dorsoventral boundary did not show any changes in Vg expression levels (Fig. $1 b-d$, arrowheads). The different effects of the reduction of Mad activity in dorsoventral boundary versus wing-blade clones is explained by the different regulatory elements that control the expression of the $v g$ gene in these regions. Mad has no effect on the Notch-dependent dorsoventral boundary enhancer, but the quadrant enhancer required Dpp signalling ${ }^{24}$ and Mad function.

To investigate whether Mad exerts a direct effect on $v g$ transcription, we tested whether Mad could bind specifically to the quadrant enhancer. SMAD family members share highly conserved aminoand carboxy-terminal domains, termed MAD homology regions 1 and $2(\mathrm{MH} 1 \text { and } \mathrm{MH} 2)^{2}$, which are separated by a less conserved proline-rich linker region. We found that the Mad MH1 plus linker, expressed as a glutathione $S$-transferase (GST) fusion protein $\left(\right.$ designated $\left.\mathrm{Mad}^{\mathrm{N}}\right)$, bound DNA and protected a single interval within the quadrant enhancer in a DNase I footprinting experiment (Fig. 2a); GST and the GST-MAD linker plus MH2 fail to bind DNA (data not shown). The specificity of Mad binding to these protected sequences was demonstrated by a gel mobility-shift assay (Fig. 2b). A 39-base-pair double-stranded oligonucleotide of the $v g$ quadrant enhancer containing the Mad-protected region, the $\mathrm{Q}^{+}$probe, was bound readily by $\mathrm{Mad}^{\mathrm{N}}$ (Fig. 2b, lane 2). A double-stranded oligonucleotide in which $12 \mathrm{bp}$ of the $\mathrm{Mad}^{\mathrm{N}}$ protected region was replaced with two $B g l I I$ restriction sites, the $\mathrm{Q}^{\mathrm{m}}$ probe, was bound with much lower affinity than the wild-type sequence (Fig. 2b, lane 7). Moreover, the $\mathrm{Q}^{\mathrm{m}}$ mutant oligonucleotide did not compete as efficiently as the $\mathrm{Q}^{+}$oligonucleotide with the ${ }^{32} \mathrm{P}$-labelled $\mathrm{Q}^{+}$probe (Fig. 2b, compare lanes 3 and 4 with lanes 5 and 6). These data suggest that the binding of $\mathrm{Mad}^{\mathrm{N}}$ protein to the quadrant enhancer 